\section{A European Enterprise}

\section{E. N. Shaw}

Ten West European States, as reported in Europhysics News of March 1971, have agreed on a major extension to the experimental facilities of CERN - the European Organization for Nuclear Research - whose existing laboratory straddles the Franco-Swiss border, west of Geneva. At a time when the growth of many national scientific budgets is being braked and some are actually reduced, it is useful to consider the nature of this extension and the operational framework of the Organization to whom it has been entrusted. The new agreement must be interpreted as a vote of confidence not only in the value of the physics that is being done at CERN but also in the principle and operation of international collaboration at it is practised there.

\section{The Accelerators at CERN I}

Two proton accelerators were envisaged in the original Convention signed in 1953: a synchro-cyclotron of $600 \mathrm{MeV}$ and a proton synchro- tron of "more than $10 \mathrm{GeV}$ ". This machine which from the beginning worked so well, has been the subject of continuous improvement ever since.

The proton synchrotron (PS) that was built has a maximum energy potential of $28 \mathrm{GeV}$ and operates mostly at about $24 \mathrm{GeV}$, its optimum level for meson production at which energy it can be cycled at once every $2.4 \mathrm{~s}$ with a $500 \mathrm{~ms}$ flat top and beam intensities of $2 \times 10^{12}$ protons per pulse. Because of the large number of potential clients for the machine, much emphasis has been placed on beam sharing and on developing beam extraction techniques.

Distributed round the circumference of the machine are three internal target stations, three points from where bunches can be fast ejected, and one point where the beam can be peeled off over a period of several $100 \mathrm{~ms}$. From these various points radiate the beam lines of protons or secondary particles and at any one time there may be as many as a dozen separate simultaneous users.

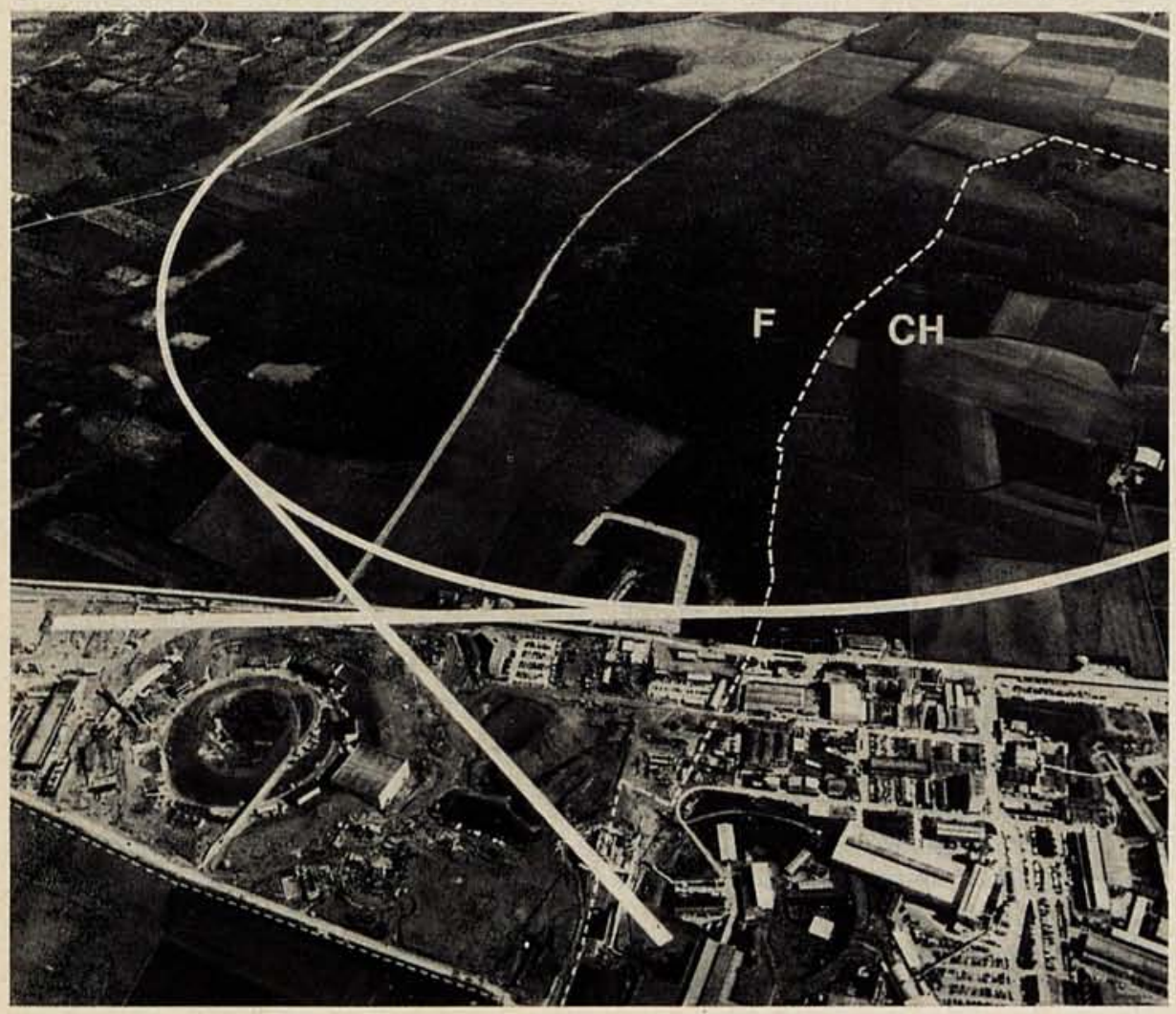

A $2 \mathrm{~m}$ hydrogen bubble chamber is currently in regular operation capable of making three separate expansions during one acceleration cycle of the synchrotron. A $3.7 \mathrm{~m}$ hydrogen chamber (BEBC) with a $3.5 \mathrm{~T}$ superconducting magnet is being built under a tripartite arrangement with two Member States (France and Federal Republic of Germany).

A special beam line for neutrino physics has also come into operation recently, the detector being a $4 \mathrm{~m}$ heavy liquid bubble chamber called Gargamelle built by the CEA of France. As with the $3.7 \mathrm{~m} \mathrm{H}_{2}$ chamber, these instruments form a normal part of the equipment of CERN with equal access by all Member States.

Usually electronic detectors and associated equipment are in part built by the research teams in their own laboratories and erected at CERN for a limited period. There is, however, now under construction a big, versatile, spark chamber assembly (Omega) in a large-volume superconducting magnet which will provide a common research facility of great flexibility. Both Omega and BEBC are scheduled to be operational in 1972 when the synchrotron booster should also be ready. This injector synchrotron to be inserted between the present $50 \mathrm{MeV}$ linear accelerator injector and the PS will raise the injection energy to 800 $\mathrm{MeV}$. When this novel four-ring high, $50 \mathrm{~m}$ diameter, slow cycling synchrotron comes into operation, beam intensities of $10^{13}$ protons per second will be obtainable at near the top energies.

Over the past 14 years the synchrocyclotron has supported a full programme of research and has undergone progressive improvement. An underground laboratory was added in 1968 to house the ISOLDE (isotope on-line) project, a most successful laboratory for the analysis of shortlife radio isotopes of particular interest to the Scandinavian members. During 1972 major engineering changes to the accelerator will increase the internal beam current from its present $1.5 \mu \mathrm{A}$ to $10 \mu \mathrm{A}$ and provide an extracted beam intensity of $10^{13}$ as against $5 \times 10^{11}$ proton $/ \mathrm{s}$.

\section{Intersecting Storage Rings at CERN I}

At the end of 1965, authorization was given for Intersecting Storage Rings (ISR) to be built which would be filled by the existing proton synchrotron. As reported in Europhysics News of March 1971 this project is nearing completion and already remarkably successful tests have been performed proving the validity of the 
original design concepts and the high quality of the construction.

\section{Technology}

Although technological development is only incidental to the main purpose of CERN, important contributions are made to advanced technology. For example, the Intersecting Storage Rings form the largest and most complex ultra-high vacuum system in Europe; the magnet of the Omega project and of the Big European Bubble Chamber are the most significant superconducting installations, a prelude possibly to the use at a later stage of pulsed superconducting magnets for the CERN II accelerator. The detectors and logic circuits in electronic computer experiments have given the lead to the development of high voltage nanosecond techniques.

Early on, the importance of data processing and computer techniques was recognized and long-term planning maintained the facilities in tune with demand. Until recently, the demand was doubling every year; now it is doubling every two years.

One of the very first CDC 6600 computers was delivered to CERN, which with a CDC 6500 and two smaller computers form the basis of the central complex. They will soon be superseded by a system based on a CDC 7600. There are on site altogether, including those brought by visiting experimental groups, some 70 computers, many working on-line with experiments or with bubble chamber film measuring equipment.

\section{Experimental Staff}

CERN has set out to be not simply a centre of experimental expertise, equipped with the best apparatus available, but a service centre and meeting point for the 100 and more universities and research centres within its Member States where high energy physics is studied. In general, experiments are carried out by mixed teams of scientists, the majority of whom will be from outside CERN and not staff members. Current estimates place the number of experimental physicists in Europe who are totally dependent upon the CERN I accelerators at about 1200 . Of these, less than 50 can be called permanent staff members of CERN whilst approximately 100 will be on the staff with medium-term contracts at any given time and a further 200 will be at CERN as fellows and visitors paid by the Organization. In addition to these, the average number of scientists working at CERN but not on its payroll will be in the region of 450 . This last figure does not include the many scientists from all over the world who visit CERN for a period of a few days only, nor the over 100 students who spend their summer vacation at CERN. The regular staff of CERN amounts to some 3000 people.

\section{CERN II}

The project for CERN II includes the construction of a new accelerator, the Super-Proton-Synchrotron, its operation over a certain period, the provision of beam lines to serve the CERN I experimental facilities and the preparation of new experimental zones on the site of CERN II. The participating States are committed to the whole of the programme, viz. eight years or until the CERN Council decides the programme has been completed, whichever is the sooner.

The accelerator is planned to give maximum flexibility during the programme and in the years to follow, so as to take advantage of technological innovations and to optimize the output for the money available. A determining feature is the major diameter of the synchrotron ring, set at $2.2 \mathrm{~km}$, and its position relative to the existing CERN synchrotron which is to act as injector to the new machine.

The design has been evolved by over 100 accelerator specialists working in the major accelerator laboratories in the Member States and many novel features are incorporated. It is based on the missing magnet concept which allows the number of magnets to be fitted to the energy required. In the first place iron-cored bending magnets to fill half the ring and sufficient for $200 \mathrm{GeV}$ will be ordered, while the focusing magnets will have an initial capability of $500 \mathrm{GeV}$. In 1973 the decision will be taken whether to add sufficient magnets to achieve $300 \mathrm{GeV}$, or fill the ring to get $400 \mathrm{GeV}$ or again to start operation at $200 \mathrm{GeV}$ in the fifth year of the programme and then install superconducting magnets in the empty spaces. These magnets giving a field of $5 \mathrm{~T}$ would allow beams of $500 \mathrm{GeV}$ protons to be produced - an energy which could be doubled if the existing iron-cored magnets were replaced by superconducting ones. The number of additional staff required for the programme is about 800 .

\section{Success Factors}

The factors which have contributed to the development of CERN are manifold. The absence of any military or immediate commercial aims is certainly a great simplification but there are many positive elements - scientific, governmental and institutional. To start with, the basic aims of the Organization were clearly established and the means quite closely defined.

\section{Scientific Consensus}

Physicists should take the credit for having arrived at such a clear consensus of opinion as to the direction which research should take, the priorities to be adopted and the means to be used. There is not unanimity throughout the field, of course, the consensus is a dynamic one, and the existence of CERN which in turn led to the formation of the European Committee for Future ACcelerators, has ensured that there is always a platform for consultation.

It must be emphasized that CERN neither dictates the programme of research nor does it seek to concentrate the research within its own organization; rather it provides a research facility for the physicists in its Member States, who can also participate actively in the forward planning of the programme of the central Organization.

\section{Government Trust}

At the government level, a great sense of internationalism is necessary as the scientific arguments must be taken on trust. Indeed, when in the early 1950's CERN was first mooted, and then in 1953 the CERN Convention was signed, this was a major act of faith by governments, particularly, as they were consenting to the construction of a type of accelerator - a strong-focusing synchrotron never before built.

Since then, a deep and harmonious relation has developed between the CERN administration and the delegates of the Member States at both the personal and official level. CERN is fortunate in having had many national delegates representing from the beginning, their country on its Council, and the resulting trust between management and delegations is of the greatest value.

Scientific and political decisions can, however, only be implemented through institutions, and many aspects of CERN have contributed to its smooth evolution and ability to move with the times and adapt itself to changing circumstances.

\section{Institutional Factors}

The Convention establishing the European Organization for Nuclear Research which superseded the Conseil Européen pour la Recherche Nucléaire was very much a permissive Convention rather than one which 
sought to restrict the activities of the Organization. It allowed a dynamic modus vivendi to evolve in which practices are able to grow rather than follow pre-set rules.

The supreme body of CERN is the Council composed of two members per Member State, all of which are equal as to voting rights. No country holds the right of veto except for a fundamental change in long-term commitments such as the admission of a new member or a change in the definition of a basic programme. No particular country more than any other has this right. Traditionally, Council members comprise one scientist and one government administrator, which ensures a partnership between the scientific and administrative elements in the Member States with CERN that is of the highest importance. Whilst the Convention lays down the majorities for the approval of decisions, it is rare for CERN to take a decision that does not finally have the backing of all, or nearly all its Members.

Responsible to the Council are the Directors-General of the two laboratories and no-one else. Their freedom of action is unusually wide and their sense of responsibility to both CERN as an organization and the Member States as individual countries is correspondingly high. They are personally totally accountable for everything that happens in their own laboratory, and the Member States make no attempt to interfere in the day-today running of the centres.

CERN has the right to invite visiting scientists from non-member states to work at the Laboratories and between 50 and 100 may be found at CERN I at any one time. The majority of the people working at the Laboratories are naturally drawn from the Member
States but it should be noted that there is no formal allocation of posts according, for example, to Members' contributions. There has similarly been no regional allocation of equipment contracts, the principle being to buy the best at the lowest price.

Members' contributions are calculated every three years on the basis of their net national revenues. The budgets are voted for a rolling period of four years, that for the next year being precise, for the year following, a firm undertaking and for the two subsequent years, firm guidelines.

The Council is assisted by a Scientific Policy Committee and a Finance Committee, but whereas the latter is composed of State representatives whose task is to survey the expenditure of CERN, the Scientific Policy Committee which plans the broad lines of scientific development consists of leading European scientists chosen in their own right and not on account of their country of origin.

\section{Experimental Procedure}

Physicists wishing to undertake an experiment on one of the accelerators, must first propose this to a completely independent committee chaired by a person outside CERN. The proposal will be studied as to its scientific value, its technical feasibility and the competence of the proposer to carry it out. In the main, successful proposals are the result of joint efforts and the majority of the experiments involve scientists from more than one external research centre (and country for that matter) with people on the medium term staff list of CERN.

Once an experiment has been agreed, the experimental team is responsible to see that what is done is good physics, and most of the

\section{CERN Member States and Budget Figures}

\begin{tabular}{|l|c|c|}
\hline \multicolumn{1}{|c|}{ Member States } & $\begin{array}{c}\text { Contributions } \\
\text { to Basic Programme } \\
\text { 1969-1971 }\end{array}$ & $\begin{array}{c}\text { Contributions } \\
\text { to CERN II } \\
\text { Programme }\end{array}$ \\
\hline Austria & $\%$ & $\%$ \\
Belgium & 1.96 & 2.01 \\
Denmark & 3.77 & 3.88 \\
France & 2.26 & - \\
Federal Republic of Germany & 19.90 & 20.48 \\
Greece & 23.27 & 23.96 \\
Italy & 0.60 & - \\
Netherlands & 12.89 & 13.27 \\
Norway & 4.43 & 4.56 \\
Sweden & 1.52 & 1.57 \\
Switzerland & 4.59 & 4.72 \\
UK & 3.20 & 3.30 \\
\hline
\end{tabular}

Total Budget for CERN I for 1971

Budget for CERN II for 1971

Total cost of the CERN II Programme at 1970 prices

Equilibrium Annual Budgets forecast CERN I+CERN II at 1970 prices
353.4

1150 MSWF.

486 MSwF. members of these teams, let it be remembered, are not CERN staff.

Member governments do not seek to control the experimental procedures, nor do they try to obtain special rights on the equipment. There is no question of a given State exacting so many hours of beam time on the PS or demanding a certain percentage of the bubble chamber pictures taken, because its contribution to the budget is a given figure.

Co-operation with Non-Member States

From the beginning the clauses in the Convention concerned with collaboration have been interpreted in a wide sense and close relations have been built up with high energy physics laboratories outside the Member States. At first, thanks to ease of communications, this was principally with the United States but progressively closer relations have been established with first the Joint Nuclear Research Centre at Dubna and now with Serpukhov. A formal agreement of July 1967 with the USSR provides for a joint scientific and technical programme using the $76 \mathrm{GeV}$ proton synchrotron at the USSR Institute of Physics at Serpukhov.

Under the terms of this agreement, CERN provides equipment for the extraction and separation of proton beams from the accelerator (to be delivered this summer) and in return is able to propose joint experiments on the accelerator. One of the first major experiments at Serpukhov was carried out by a joint Soviet-CERN team and considerable enthusiasm has been expressed by both communities, for the success of this enterprise, for the scientific interest of the results as well as the harmonious personal relations that developed. The second experiment which has now been operating for over six months involved the shipment to Serpukhov of some 200 tons of equipment.

In addition to arrangements with the Soviet Union there has been close collaboration with laboratories in Poland which, with Turkey and Yugoslavia, has the distinction of being an Observer State of CERN. This status of observer has more symbolic than contractual significance, as all the work conducted at CERN is published. Observer countries do, however, have the right to attend Council sessions, if not to vote, and the position assures a certain intimacy and special relationship.

CERN does not have close relations with developing countries as its contacts are dependent upon the existence of advanced high energy physics facilities in a given country. 


\section{Conclusion}

In such a summary of the way in which CERN contributes to European physics, only some of the salient aspects can be indicated. It should none the less be clear that CERN so often quoted as the best example of European collaboration - is an organization that depends upon a strong consensus of the physics community coupled to the dedicated support of the governments of its Member States and their delegates.

In the early days there was a natural fear that the creation of a strong centre for research would deprive universities and national research centres of their best people ; the end result would be an impoverishment of the Member States rather than their enrichment. The reverse has proved to be the case, and the current policy of CERN is strongly directed towards ensuring a throughput of people and avoiding a sink. Physicists and administrators recognize that, with limited overall budgets, an international laboratory while absorbing funds which might be available for spending at national centres, is the most efficient way of maintaining university and national research centres at the highest level in this area where large expensive machines are necessary.

\section{Society News}

\section{Individual Ordinary Members}

In the election of Delegates to Council 575 votes were received from Individual Ordinary Members and as a result the following two members will be delegates to the Council taking office in 1971:-

\section{G. Harbeke, Affoltern \\ W. Klose, Saarbrücken}

Günter Harbeke, born 1929, received the Physics Diploma in 1955 and the Ph. D. in Physics in 1958, both from the Technical University in Brunswick. From 1958 to 1961 he worked at the Physikalisch-Technische Bundesanstalt in Brunswick. In 1961 he joined the RCA Laboratories, Zürich, where he is presently engaged in solid state research. He received the "venia legendi" in physics from the University of Hamburg in 1968 and became Honorarprofessor at Cologne University in 1970.

Wolfgang Klose, born 1930, Diplom-Physiker (1953) with experimental work on exo-electrons; thesis (1956) on a theory of secondary electron emission (Berlin). Until 1961 he was at the PhysikalischTechnisches Institut, Deutsche Akademie der Wissenschaften, Berlin. From 1961 to 1967 he worked at the Siemens Research
Laboratories in Erlangen. Since 1967 he has been Professor for theoretical solid state physics in Saarbrücken. His fields of activity are electrical and thermal conductivity of metals and semiconductors, superconductivity and surface problems.

We are sorry that owing to the postal strike, votes from Members in the UK were not received in time for the count on 18 March.

\section{Member Societies}

On 18 March 1971 the Council accepted as a Member according to Article $4 \mathrm{~b}$ of the Constitution the Physical Society of the German Democratic Republic. This Society has 810 members ; its president is R. Rompe and its secretary R. Linke, at the following address: Physikalische Gesellschaft der Deutschen Demokratischen Republik, Am Kupfergraben 7, DDR - 108 Berlin.

A Royal Charter has been granted to the Institute of Physics and the Physical Society, which will now have the title of The Institute of Physics.

\section{Associate Member}

The following organization has decided to join the European Physical Society as Associate Member

IBM Europe, Paris, France.

\section{New Individual Ordinary Members}

The following have been accepted as Individual Ordinary Members of the European Physical Society :
M.A. Aegerter, Neuchâtel
F. Agullo-Lopez, Madrid
F.W. Albrecht, Sindelfingen
G.R. Allcock, Liverpoo
O.K. Andersen, Copenhagen
. Arechi, Milan
.Ch. Arnbak, Hørsholm
A.M.G. Bakker, Amsterdam
A.M.G. Bakker, Amsterd
A. Bardocz, Garching
G. Barton, Brighton
G. Barton, Brighton
G. Ben-David, Yavne
R. Benjamin, Aiken
J.B. Bergström, Stockholm
E.F. Bertaut, Grenoble
J.M. Bewers, Dartmouth
D.A. Blackburn, Bletchley
K. Böckmann, Gene
H. Bolouri, Berlin
B. Bonnevier, Stockholm
M. Bowler, Oxford
W. Braunschweig, Bon
1. Bucher, Baltimore
$\mathrm{H}$. Burkhardt, Birmingham
A. Carter, Cambridge
A. Carter, Cambrillejo, London
L.J. Challis, Nottingham
L. Chanin, Excelsior
R. Chisleag, Bucharest
F. Climent, Barcelona
P.F. Cornaz, Lausanne
M. Corti, Milan
G. Costa, Bari
R. Crafer, Hull
R. Dändliker, Oberrohrdorf
D.P. Dallman, Vienna
V. de Alfaro, Turin
J.E.P. de Bie, Amsterdam
V. Degiorgio, Milan
$M$. de Jong, Eindhoven
M. de Leizaola Elejalde, Bilbao
A. de Marco, Turin
F.F. Derqui-Morilla, Madrid

G.W. Holzer, Paris
B. Hyams, Geneva
D.C. Imrie, Ruislip
J. Jäckle, Geneva
T. Jaeger, Kjeller
W. Kaiser, Munich
R. Kersten, Aachen
A. Khan, Karachi
A. Kildai, Oslo
R. Klapisch, Orsay
D. Klüppelberg, Neckargemünd
H.F.P. Knaap, Leyden
B. Koch, Loerrach
H.G. Kramers, Leiderdorp
T. Kunjukrishnan, Singapore
P. Lallemand, Paris
D.Q. Lamb, Rochester
G.L. Lamb, East Hartford
L. Lapikas, Amsterdam
B. Lauriou, Algiers
J. Lefrançois, Orsay
G.-A. Leman, Lille
R. Levy, Strasbourg
G. Lewis, Glasgow
J. Lopes, L'sbon
K. Lübelsmeyer, Bonn
R. Lüst, Munich
T.D. MacMahon, Ascot
J.V. Major, Durham
J. Malos, Bristol
M.W.D. Mansfield, Surbiton
P. March, London
E. Martinho, Sacavem
J.N. Mathur, Wollongong
P.T. Matthews, London
O.E. Mogensen, Roskilde
R. Moreh, Beer Sheva
G. Mosinski, St. Maurice
P. Montcouronne
P. Murphy, Manchester
A. Mustafa, Damascus
A.V. Narlikar, Kolhapur
F. Navach, Geneva
D. Newton, Lancaster
J.C. Normanha Salles, Campinas
K.J. Nygaard, Rolla
M.J. Offerhaus, Amsterdam

P. Osland, Trondheim

A. Paulin, Zurich

H. Persson, Stockholm

K. Peterson, Lyngby

W. L. Posthumus, Amsterdam

W.L. Posthumus, Am
D. Reading, Chilton

M. Richardson, Ottawa

E. Riihimäki, Helsinki

K.F. Riley, Cambridge

R. Ritter, Geneva

D. Rivers, Hong Kong

G. Rivoire, Angers

R.L. Rouse, Wemble

J. Rutherglen, Glasgow

E. Santos, Valladolid

Sauli, Genev

M. Schaldach, Erlangen

H. Schindler, Wupperta

K.R. Schubert, Geneva

A. Schultz von Dratzig, Bonn

A. Schultz von Drat

A. Segar, Oxford

F.M. Sequeira, Lisbon

P. Shiner, Stourbridge

P. Shiner, Stourbridge

N. Spector, Yavne

D. Sutherland, Glasgow

B. Sutherland, Gilasgow

J.G. Taylor, Southampton

G. ten Brink, Hoensbroek

E. Tennfors, Stockholm

F.J. Theiss, Berlin

A. Vendramini, Milan

A.J. Wallard, Teddington

D.L. Ward, Daresbury

M. Watering, Manchester

J. Weber, Berlin

, Berlin

J. Wiebes, Leyden

J. Williams, Cambridge

. Willis, Nambridge

R. Windmolders, Brussels

P. Winkler, Aachen

E. Witalis, Stockholm

H. Wöllmer, Goslar

P.T. Woods, Teddington

P.T. Woods, Tedaington

A.A. Yekutiel Swarthmore

J. Zak, Haifa

K. Ziegler, Rüdigheim 